\title{
CETA AND ITALIAN AGRI-FOOD PRODUCTS: AN ANALYSIS ON COMPARED ADVANTAGES OF THE MAIN ITALIAN AGRI-FOOD SECTORS
}

\begin{abstract}
Daniele BERTOLOZZI CAREDIO, Department of Agriculture, Food and Environmental Science, University of Perugia, Piazza Università, 106123, Perugia, Italy, danielebertolozzi@gmail.com

Asta RAUPELIENE, Institute of Business and Rural Development, Aleksandras StulginskisUniversity, Universiteto 10, LT-53361, Akademija, Kaunas dist., Lithuania, asta.raupeliene@asu.lt (coresponding author)

At the age of second-generation agreements, the European Union is going to achieve a number of new trade deals, as well as others country, first of all the Comprehensive Economic and Trade Agreement treated with Canada. A significant part of the debating about CETA is focused on the real need or not to reach new deal and add more liberalization, in particular regarding the Agri-food goods. EU, and above all Italy, can boast a number of excellent export Agri-food processed product, such as wine, cheese and pasta; at the same time, Italy has a need of primary goods, like wheat. Revealed Competitive Advantage is an indicator of the importance of a specific product and, specifically, it's used to identify the advantage or disadvantage of a trade flow. Some of the main Italian products exported in Canada have been analysed, just like the main imported product from Canada, the wheat; as opposed to EU-28 import of Durum wheat, the other trades have showed a comparative advantage in trade. Finally, in three cases, Italy proves greater advantages in respect with the EU.
\end{abstract}

Keywords: Agri-food production; Comprehensive Economic and Trade Agreement (CETA); Revealed Competitive Advantage (RCA)

\section{INTRODUCTION}

The stall of the Doha Round and the slow progress of the relative agreements have pushed many countries to reach a more liberalized state of trade through the negotiation of bilateral deals. This new deals are named second-generation free trade agreements (FTA), cause their wide contents concerning non-tariff barriers, harmonization and a considerable level of integration in all the economic sectors. European Union, since a ten year, is achieving a number of bilateral second-generation FTA, for instance with China, Mercosur, Japan and Canada. While the large part of these negotiations have to be terminated, the Comprehensive Economic and Trade Agreement (CETA) is the greatest second-generation FTA concluded with EU until now.

The CETA, accorded with Canada, has a wide field of application: from Agri-food sector to service, from industry to intellectual property. It concerns remarkable matters such as Geographical Identification protection, elimination of non-tariff barriers and harmonization of the rules. But over these new frontiers, about the Agri-food sector the reduction of tariff barriers (TB) is still significant. Whether a large part of goods, like manufacturing products, show on average a lower level of TB, the agricultural trade (together with textile sector) faces a higher level of TB. That is, the eventual decrease of TB is more important for agriculture, comparing to the other sectors.

As it's known, Italy is a net exporter of processed agricultural goods and an importer of primary products. In the light of CETA, is somewhat important to define which benefits and opportunities Italy can obtain from the new trade rules.

Considering that wine, cheese and pasta are the main Italian foodstuffs exported in Canada, and that Durum wheat is the most important agricultural product that Italy import from Canada, measure their importance relative to agriculture sector, can lead to find a general convenience (or threat) in CETA effects on Italian Agri-food area; or rather, advantages and disadvantages of the main trade products can be connected to a general advantage or disadvantage for the entire agriculture sector, although this can't be a fully representative of reality.

In fact, statistical data prove the relative importance of these goods in respect of agricultural trade. According to the data source of the International Trade Ceneter, in 2016 the wine (HS4 2204) represents almost the $40 \%$ of the entire agricultural export from Italy to Canada, followed by "cheese" (HS4 0406) which represents the 5,9 \%, and by "pasta" (HS4 1902) with the 4,9\%. Together, these goods represent more than half of the Italian Agri-food export in Canada. Moreover, these numbers acquires a major value knowing that Italian agricultural export worth the $20,7 \%$ of the total

Copyright (C) 2017 The Authors. Published by Aleksandras Stulginskis University. This is an open-access article distributed under the terms of the Creative Commons Attribution License (CC-BY 4.0), which permits unrestricted use, distribution, and reproduction in any medium, provided the original author and source are credited. 
export flow towards Canada. About the Italian import from Canada of vegetable products and foodstuffs, the durum wheat (HS4 1001) covers the $54,5 \%$ of the agricultural trade flow from Canada.

In order to determine the existence of advantages, Revealed Comparative Index (RCA) can be used. The RCA index is used in international economics to determine the relative advantage or disadvantage of a certain country in a certain class of goods or services; it means that the balance index is applied to identify sectors and markets that have the greatest likelihood of success (Granabetter D., 2016).

The results of the calculation concur to detect the benefits that CETA could provide to the Italian Agri-food sector, as well as to reveal a comparative advantage for wine, cheese and pasta products. Finally, the analysis compares the advantages of Italian Agri-food sectors with the European ones, with the aim of measure the difference between those two advantages.

The aim of this study is to identify the presence of comparative advantages in some of the main Italian Agri-food sectors, and compare the results to the European level.

Objectives:

1. The identification of the eventual existence of comparative advantages, through the calculation of RCA index.

2. Calculate the RCA index of the same goods for the entire EU-28 and compare these to the Italian RCA results.

3. Identify in a qualitative way a possible general advantage for the Italian Agri-food sector in trade with Canada.

\section{METHODOLOGY}

Comparative advantage is the result of a refining of absolute advantage made by Ricardo. According to Ricardo, a country tends to allocate its resources to their most productive use and, at a time, to import goods of which it is the lowest cost producer.

Eli Heckscher and Bertil Ohlin revolutionized trade theory by emphasizing international differences in resources (or factor) endowments. The $\mathrm{H}-\mathrm{O}$ model, predict that a country will export commodities that are relatively intensive in the factor with which the country is relatively well endowed. The purview of the H-O model has been subsequently extended through the work of Wassily Leontief, Paul Samuelson, Jaroslav Vanek and others (Leishman D. et al., 1999).

In order to reach the objectives and evaluate any advantages in specific trade flow, it has been used a common index, the Revealed Comparative Advantage index, or also named Balassa index. In truth, the original RCA index was formulated by Balassa (1977, 1986), although several alternative measures have been suggested (Fidan H., 2009).

The RCA index is used to analyse different sectors, particularly in agriculture. This index is usually applied to identify the main destinations and product groups for the region's export trade, namely to determine its development and often it's used to calculate the relative advantage or disadvantage of a certain country in a certain class of goods or services (Granabetter D., 2016).

In theoretical models, following the international trade theory and considering the concepts expressed by Ricardo and subsequent ones, comparative advantage is calculated on the base of the relative prices in autarky, or rather in the absence of trade. Since that every country has at least a minimum of the trade relationship, these prices can't be observed; as a consequence, comparative advantage is measured indirectly.

Revealed comparative advantage index is a way to approximate comparative advantage in autarky; in fact, according to Balassa, on the assumption that the commodity pattern of trade reflects inter-country differences in relative costs as well as in non-price factors, this is assumed to reveal the comparative advantage of trading countries are also, if trade performance is determined by comparative advantage, then direct observations of trade performance should reveal comparative advantage (Balassa B., 1977).

"Revealed comparative advantage indices use the trade pattern to identify the sectors in which an economy has a comparative advantage, by comparing the country of interests' trade profile with the world average. The RCA index is defined as the ratio of two shares. The numerator is the share of a country's total exports of the commodity of interest in its total exports. The denominator is share of world exports of the same commodity in total world exports" (Mimik M. et al., 2007).

According to Ferto I. (2002), the revealed comparative advantage index for import trade is named as RMA.

RCA of export trade: $\quad R C A_{i j}=\frac{X_{i j} / X_{w j}}{X_{i t} / X_{w t}}$

RCA of import trade:

$$
R M A_{i j}=\frac{M_{i j} / M_{w j}}{M_{i t} / M_{w t}}
$$

Where:

RCAij: export index value for country $i$ in the commodity/sector $j$

RMAij: import index value for country $i$ in the commodity/sector $j$

$X$ : export value

$M$ : import value

$i$ : country of interest

$j$ : sector/commodity of interest

$t$ : set of commodities

$w$ : set of countries 
In this study, the objects of interest are Italy and the European Union ( 28 members) and the commodities of interest are wine, cheese, pasta and wheat. They have been compared with a set of countries that include all the world countries, and a set of agricultural commodities included in HS2 between codes 1 and 24, that is a set of all agricultural products.

Furthermore, the Italian and European values of trade has been subtracted from the world's trade value, because of their quantitative relevance relative to the world trade.

The index assumes a value included between 0 and $+\infty$; if the result exceeds unity $(>1)$, the analysed country has revealed comparative advantage in the sector or commodity of interest; to the contrary, if the value was less than 1, the country would show a comparative disadvantage. Indeed, as Hinloopen and Van Marrewijk (2001) proposed, RCA index value can be divided into 4 classes: without comparative advantage (RCA $<1)$ or with weak $(>1)$, medium $(>2)$ and strong (>4) comparative advantage.

Although RCA is affected by any distortion of trade model, compared to others indices this method is more descriptive and, generally, the necessary data are easily available.

The data used to perform the RCA analysis have been obtained from the International Trade Center database, which is the Trademap. A period of ten years was chosen, from 2007 to 2016.

The categories of goods are selected through the harmonized system (HS), in particular the groups are identified by the 4 digit code (HS4). Therefore, for wine is meant "wine of fresh grapes, including fortified wines; grape must other than that of heading no. 2009" (HS4 2204); for cheese is meant "cheese and curd" (HS4 0406); for pasta is meant "pasta; whether or not cooked or stuffed with meat or other substance, or otherwise prepared, egg spaghetti, macaroni, noodles, lasagne, gnocchi, ravioli, cannelloni; couscous, whether or not prepared" (HS4 1902); for durum wheat is meant "cereals; wheat and meslin, durum wheat, other than seed" (HS4 1001).

\section{RESULTS}

The main objective of the study is to identify the presence of comparative advantages in some of the main Italian Agri-food sectors, and compare the results to the European level. To develop the analysis, statistical data are required. Table 1 shows, trade values in a period between 2007 and 2016, that is a decade; trade flow is divided in export flow for wine, cheese, pasta and Agri-food sector, and in import flour for wheat and Agri-food sector. The used data concern three subjects: Italy, European Union and World. Through these data, is possible to apply the proposed method to identify comparative advantage.

The trade values in the table 1 shows the importance of Italian export trades relative to the same trade in European and world level, moreover each of those have increased in the decade. Obviously, the EU-28 trade flow are remarkable compared to the world flows, and even these have increased in the period of interest, as Italian flows. But this point of view is not enough to reveal comparative advantage.

The revealed comparative advantage index has been calculated for 4 commodities: wine, cheese, pasta and wheat. First, RCA results of the Italian trade flows of interest, that are wine, cheese and pasta, have always shown a value higher than 1. As observed in table 2, the wine export shows a RCA value between 5,98 and 8,30, with a value in 2016 of 7,91, high but not the highest; cheese export, reaches a value of 3,74 in 2016, with not significant changes in the period of interest; finally, the pasta export achieve the highest value, reaching a RCA of 14,50 in 2016, with changes in the decade between 15,50 and 20,42. On the other hand, RCA of Durum wheat import has just reached the value of 1,54.

On the European side, the calculated indices for export products always exceed the unity, as opposed to the import flow of wheat that appears less than 1. As shown the tables 2, cheese export reached the highest value, touching the 4,55 in 2016; wine export index reach 3,02 in 2016, while the pasta export index has the value of 1,35. All the export trade has shown a significant decrease during the decade. About the wheat import, the index has never passed the unity.

\section{CONCLUSIONS}

The results of the analysis bring to light some observations, which respond to the objectives proposed by this study. First, Italian export trades of the three main Agri-food goods showed high and significant value of RCA; in the case of pasta, wine and cheese, the revealed comparative advantage can be named as strong for the first two and medium for the third. Instead, the calculation developed in Durum wheat import trade in Italy has shown a weak comparative advantage.

About European trade, the value reached by cheese, wine and pasta export revealed respectively strong, medium and weak comparative advantage; he European import of durum wheat has shown a very low value, as a result, it proves the presence of a considerable comparative disadvantage.

In the cases of wine, pasta and wheat Italian RCA values generally exceed the European ones; to the contrary, EU28 cheese export advantage, despite the decrease, is higher than Italian one, which increase in the decade.

Considering what has been shown, Italy succeeds in trading commodities of interest, in particular presents great potentials in wine and pasta sectors. Being Canada an important target for Italian Agri-food export flow, the liberalization of trade and integration of both European and Canadian markets, due to CETA, can potentiate and increase the export value, providing new income for main Italian Agri-food sectors.

European Union presents lower comparative advantages in wine and pasta export than Italian ones. It means that, regarding wine and pasta export, Italy has a major interest in CETA and more benefits in decrease tariff barriers. However, also EU can obtains opportunity for the application of the new agreement. 
Proceedings of the $8^{\text {th }}$ International Scientific Conference Rural Development 2017

Table 1. Export and import trade, values in thousand euro

\begin{tabular}{|c|c|c|c|c|c|c|c|c|c|c|}
\hline \multirow[b]{2}{*}{ Italy } & 2007 & 2008 & 2009 & 2010 & 2011 & 2012 & 2013 & 2014 & 2015 & 2016 \\
\hline & & & & & & & & & & \\
\hline Wine export & 3.543 .500 & 3.665 .063 & 3.507 .654 & 3.907 .900 & 4.402 .158 & 4.693 .107 & 5.038 .992 & 5.108 .051 & 5.384 .174 & 5.621 .995 \\
\hline Cheese export & 1.346 .783 & 1.452 .309 & 1.441 .691 & 1.655 .094 & 1.908 .041 & 1.975 .255 & 2.058 .160 & 2.154.377 & 2.256 .875 & 2.417 .540 \\
\hline Pasta export & 1.569 .505 & 2.033 .505 & 1.842 .318 & 1.808 .724 & 1.960 .236 & 2.090 .385 & 2.168 .997 & 2.235 .189 & 2.385 .563 & 2.345 .375 \\
\hline \multirow{2}{*}{$\begin{array}{l}\text { Agri-food export } \\
\text { Durum wheat } \\
\text { import }\end{array}$} & 24.453 .980 & 26.533 .950 & 24.881 .508 & 27.619 .512 & 29.966 .317 & 31.759 .799 & 33.312 .132 & 34.154 .534 & 36.749 .374 & 38.362 .199 \\
\hline & 1.361 .860 & 1.561 .465 & 1.244 .811 & 1.411 .737 & 1.892 .109 & 1.591 .477 & 1.494 .260 & 1.798 .410 & 1.843 .106 & 1.614 .548 \\
\hline Agri-food import & 32.364 .004 & 34.068 .704 & 32.104 .535 & 35.170 .326 & 38.625 .587 & 38.133 .176 & 39.076 .351 & 40.167 .673 & 41.357 .098 & 41.521 .706 \\
\hline \multicolumn{11}{|l|}{ EU-28 } \\
\hline Wine export & 14.733 .703 & 15.169 .263 & 13.368 .448 & 14.916 .792 & 17.107.923 & 18.433 .367 & 18.878 .001 & 18.865 .160 & 19.788 .016 & 20.028 .018 \\
\hline Cheese export & 13.001 .920 & 14.509 .401 & 12.868 .874 & 14.686 .058 & 16.337 .821 & 16.924 .484 & 18.185 .603 & 18.901 .528 & 18.124 .451 & 18.315 .645 \\
\hline Pasta export & 2.377 .971 & 2.984 .442 & 2.782 .225 & 2.817 .589 & 3.041 .375 & 3.266 .289 & 3.402 .630 & 3.514 .496 & 3.792 .058 & 3.802 .548 \\
\hline \multirow{2}{*}{$\begin{array}{l}\text { Agri-food export } \\
\text { Durum wheat } \\
\text { import }\end{array}$} & 307.329 .383 & 336.685 .136 & 317.782 .016 & 351.536 .664 & 398.961 .917 & 430.281 .677 & 453.994 .240 & 456.203 .301 & 477.717 .868 & 492.390 .905 \\
\hline & 5.558 .393 & 6.842 .719 & 5.406 .774 & 5.720 .189 & 7.254 .547 & 7.550 .538 & 7.026 .776 & 6.842 .871 & 7.296 .803 & 7.017.393 \\
\hline Agri-food import & 326.666 .142 & 358.781 .200 & 338.418 .820 & 365.565 .447 & 411.697 .965 & 431.417 .352 & 447.144 .385 & 450.972 .982 & 477.695 .079 & 488.473 .598 \\
\hline \multicolumn{11}{|l|}{ World } \\
\hline Wine export & 20.132 .043 & 20.358 .132 & 18.360 .000 & 21.078 .607 & 23.637 .167 & 25.829 .760 & 26.287 .383 & 26.151 .939 & 28.669 .752 & 29.252.204 \\
\hline Cheese export & 16.187 .540 & 18.368 .866 & 16.454 .999 & 19.275 .421 & 21.296 .446 & 22.278 .093 & 23.715 .453 & 24.769 .182 & 23.996 .778 & 23.907 .627 \\
\hline Pasta export & 4.025 .364 & 4.952 .074 & 4.873 .230 & 5.263 .812 & 5.851 .400 & 6.522 .679 & 6.859 .694 & 7.026.117 & 7.768 .541 & 7.724 .817 \\
\hline \multirow{2}{*}{$\begin{array}{l}\text { Agri-food export } \\
\text { Durum wheat } \\
\text { import }\end{array}$} & 684.186 .679 & 777.461 .458 & 737.967 .412 & 871.677 .437 & 1.008 .454 .578 & 1.119 .189 .481 & 1.142 .802 .089 & 1.167 .995 .230 & 1.257 .073 .631 & 1.276 .130 .818 \\
\hline & 24.725 .832 & 34.216 .950 & 25.063 .063 & 27.138 .803 & 37.964 .026 & 37.920 .245 & 37.280 .995 & 39.008 .937 & 37.741 .604 & 34.374 .678 \\
\hline Agri-food import & 714.594 .647 & 813.261 .656 & 767.147 .210 & 891.993 .864 & 1.039.311.781 & 1.140 .787 .222 & 1.151 .630 .082 & 1.177 .432 .500 & 1.285 .780 .254 & 1.293 .830 .081 \\
\hline
\end{tabular}

Source: Authors elaboration based on data from International Trade Center database (Available at: www.trademap.org) 
Table 2. RCA and RMA index

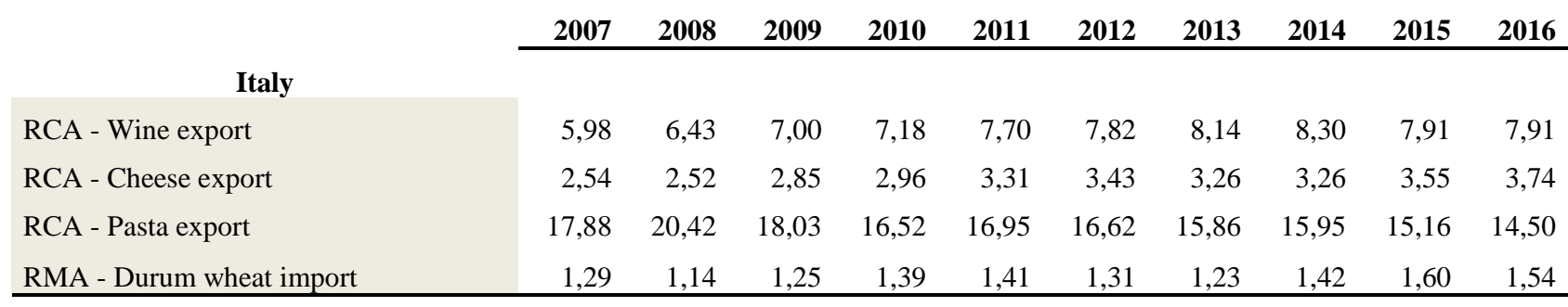

\section{EU-28}

\begin{tabular}{|c|c|c|c|c|c|c|c|c|c|c|}
\hline RCA - Wine export & 6,08 & 5,94 & 5,77 & 4,71 & 4,49 & 3,96 & 3,84 & 3,88 & 3,19 & 3,02 \\
\hline RCA - Cheese export & 9,09 & 7,64 & 7,73 & 6,23 & 5,65 & 5,03 & 4,96 & 4,83 & 4,42 & 4,55 \\
\hline RCA - Pasta export & 3,21 & 3,08 & 2,86 & 2,24 & 1,86 & 1,59 & 1,48 & 1,50 & 1,37 & 1,35 \\
\hline RMA - Durum wheat import & 0,63 & 0,50 & 0,58 & 0,52 & 0,41 & 0,41 & 0,37 & 0,34 & 0,36 & 0,38 \\
\hline
\end{tabular}

Source: Authors elaboration based on data from International Trade Center database (Available at: www.trademap.org

However, Durum wheat import presents itself as a disadvantageous trade flow in European trade; as a result, in this case there are no obvious advantages for EU in the new deal with Canada. Instead, even if weak, Italy has shown a comparative advantage in wheat import, that means a potential benefit from CETA.

In conclusion, the remarkable advantage and strength of Italian trades demonstrates, or at least promotes, a more general advantage for the Italian Agri-food sector, obtained from CETA, for the analysed goods are the main Italian products usually trade with Canada, or rather at least in part representative of the entire sector.

Only EU has shown a potential disadvantage in wheat import. Overall, the agreement can provide benefits and opportunities in the Italian and European Agri-food sectors.

\section{REFERENCES}

1. Balassa, B. 1977. Revealed Comparative Advantage Revisited: An analysis of relative export shares of the industrialized countries, 1953-1971. The Manchester school of Economic and Social Studies, Vol. 45, pp. 327-344. https://doi.org/10.1111/j.14679957.1977.tb00701.x

2. Balassa, B., Noland, M. 1989. Reveald Comparative Advantage in Japan and United States. Journal of International Economic, Integration, Vol. 4, Iss. 2, pp. 8-22.

3. Bowen, H.P. 1983. On the Theoretical Interpretation of Indices of Trade Intensity and Revealed Comparative Advantage. Weltwirtschaftliches Archiv, Vol. 119, pp. 464-472. https://doi.org/10.1007/BF0270652

4. Hubbard, L., Banterle, A. 2008. Measuring Competitiveness in the EU Market: a Comparison between Food Industry and Agriculture. 12th Congress of the European Association of Agricultural Economists - EAAE, pp. 1-5.

5. Chaudhary, A. 2016. Revealed Comparative Advantage Index: An Analysis of Export Potential of Indian Textiles Industry in the Post MFA Period. American Journal of Economics, Vol. 6, Iss. 6, pp. 344-351.

6. Ciuriak, D. 2017. Understanding CETA: An Upgrade for Canada's Global Connections. Available at: file:///d:/Users/labas/Downloads/Understanding\%20CETA\%20An\%20Upgrade\%20for\%20Canada's\%20Global\%20Connections. pdf

7. European Trade Commission, 2018. Overview of FTA and other Trade Negotiations. Available at: http://trade.ec.europa.eu/doclib/docs/2006/december/tradoc_118238.pdf

8. European Trade Commission, 2018. Creating new opportunities for your business. Available at: http://ec.europa.eu/trade/policy/infocus/ceta/ceta-explained/index_en.htm

9. Ferto, I., Hubbard, L.J. 2002. Reveald Comparative Advantage and Competitivness in Hungarian Agri-Food Sectors. Discussion Papers, MT- DP. 2002/8, pp. 1-16.

10. Fidan, H. 2009. Comparison of Citrus Sector Competitiveness between Turkey and EU-15 Member Countries. HortScience, Vol. 44, Iss. 1, pp. 89-93.

11. French, S., 2014. Revealed Comparative Advantage: What Is It Good For?”; School of Economics, University of New South Wales, pp. 1-26. Available at: http://research.economics.unsw.edu.au/sfrench/documents/French RCA.pdf

12. Granabetter, D. 2016. Revealed Comparative Advantage Index: An Analysis of Export Trade of the Austrian District Burgenland. Review of Innovation and Competitiveness, Vol. 2, Iss.2, pp. 97-114.

13. Leishman, D., Menkhaus, D.J., Whipple, G.D. 1999. Revealed comparative advantage and the measurement of international competitiveness for agricultural commodities: an empirical analysis of wool exporters. University of Wyoming. Available at: https://ageconsearch.umn.edu/bitstream/35691/1/sp99le01.pdf

14. Mimik M., Gilbert J., 2007. Trade Statistics in Policymaking. A handbook of commonly used trade indices and indicators. Economic and Social Commission for Asia and the Pacific. Available at: https://artnet.unescap.org/artnet_app/Handbook2.pdf 
15. Vitunskiene, V., Serva E. 2015. Shifts in Lithuania's Agri-food Industry Export Competitiveness: a Comparative Analysis Versus High- and Medium-high Technology Manufacturing Industries. Oeconomia Copernicana, Vol. 6, Iss. 1, pp. 7-31. https://doi.org/10.12775/OeC.2015.001

16. Raghuramapatruni, R., 2015. "Revealed Comparative Advantage and Competitiveness: A Study on BRICS"; Arabian Journal of Business and Management Review 5: 152 http://dx.doi.org/10.4172/2223-5833.1000152 